\section{Materials Research Societies provide opportunities for young materials researchers}

\author{
www.mrs.org.sg/icyram2012 \\ www.dfa.unict.it/home/terrasi
}

Tsear ast year, young materials re$U_{\text {searchers around the world took }}$ advantage of two events designed for them by their professional societies.

\section{MRS}

$\epsilon-M \mathrm{R}$

(16)

The International Union of Materials Research Societies (IUMRS) launched the International Conference of Young Researchers on Advanced Materials (ICYRAM) hosted by MRS-Singapore. And the

\section{MRS} Materials Research Society joined the European-MRS to organize the second International Summer School with a focus on "Materials for Renewable Energy," held in Erice, Italy.

The school in Erice, held July 18-28, ergy to different countries. introduced young researchers to worldleading experts who presented over 20 lectures concerning materials science relevant to the production, utilization, and storage of sustainable and renewable energy. The school also presented a global overview about the politicalsocioeconomic impact of the energy production and business of renewable energy and insight into intellectual properties and patenting. The students - representing 70 countries from North and South America, Europe, Africa, and the Middle East - presented posters and participated in a student challenge working on scenarios to provide renewable en-

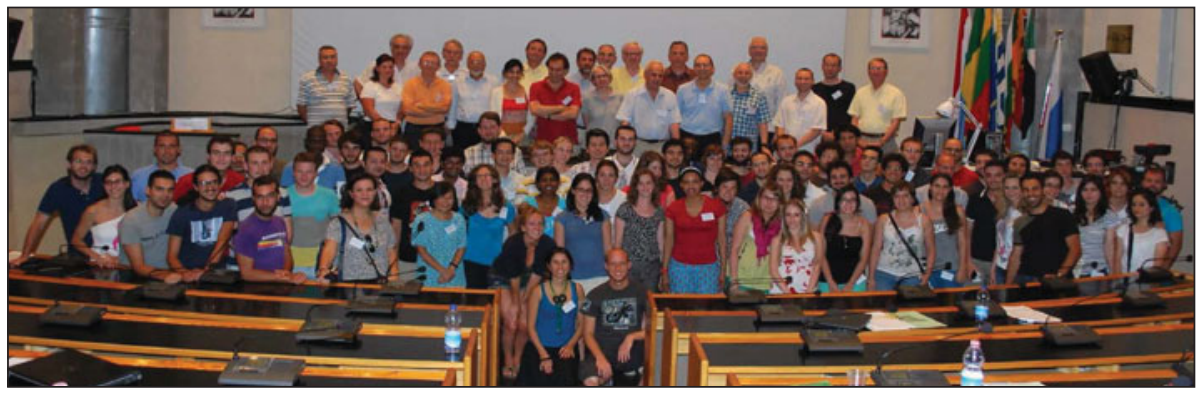

Participants of the International School "Materials for Renewable Energy" held in Erice, Italy.
The directors of the course were past MRS presidents David Ginley (National Renewable Energy Laboratory, USA) and John Poate (Colorado School of Mines, USA), past president of European-MRS Abdelilah Slaoui (InESS-CNRS, France), and from the University of Catania, Italy, Emanuele Rimini and Antonio Terrasi. The next school is scheduled for July 12, 2014.

In Singapore, IUMRS-ICYRAMheld on July 1-6 - provided a platform for researchers under the age of 40 to present technical findings of their research, to network within the international community of other young researchers, and to increase the breadth of their general materials-based knowledge. The topics presented included biomaterials and health care, carbon-based materials, energy and the environment, electronic materials, magnetic and spintronic materials, and optical materials. The young researchers heard plenary speakers on each of the subjects as well.

The local organizing committee included, from the National University of Singapore, B.V.R. Chowdari as chair and Yuan Ping Feng as technical chair, and from A*STAR, Evan L. Williams as executive chair and Mark Hyunpong Jhon as executive vice-chair. IUMRSICYRAM is planned to be a biennial meeting, with the next edition to be hosted by the Materials Research Society of China in 2014.

MSM XVIII to be held in Oxford in April 2013

www.rms.org.uk

The 18th Microscopy of Semi-Conducting Materials (MSM XVIII), sponsored by the Royal Microscopical Society (RMS), will be held April 7-11, 2013, at St Catherine's College, University of Oxford, United Kingdom.

Chaired by John Hutchison (University of Oxford) and Thomas Walther (University of Sheffield), the conference will focus on the most recent advances in the study of the structural and electronic properties of semiconducting materials by the application of transmission and scanning electron microscopy. The latest developments in the use of other important microcharacterization techniques including scanning probe microscopy, and $\mathrm{x}$-ray topography and diffraction will also be featured. Developments in materials science and technology covering the complete range of elemental and compound semiconductors will be described.

Invited speakers include Simona
Boninelli (University of Catania, Italy), Pavel Potapov (Global Foundries, Dresden, Germany), and Toshiharu Saiki (Mejo University, Kanagawa, Japan). On the evening of April 9, the RMS Annual Materials Lecture will be delivered by Sir Colin J. Humphreys (University of Cambridge, UK) on the topic of how microscopy and semiconductors can help to solve some major world problems.

The conference is endorsed by the Materials Research Society. 